\title{
Releasing thyroid cancer patients from the hospital based on dose rate measurement after ${ }^{131}$ I activity administration
}

\author{
R. Hewamanna ${ }^{1 *}$, Naalini Loganathan ${ }^{2}$ and D.K.A. Perera ${ }^{3}$ \\ ${ }^{1}$ Department of Nuclear Science, Faculty of Science, University of Colombo, Colombo 03. \\ ${ }^{2}$ Postgraduate Institute of Science, University of Peradeniya, Peradeniya. \\ ${ }^{3}$ National Cancer Institute, Maharagama.
}

\begin{abstract}
The treatment of thyroid cancer generally comprises total thyroidectomy and oral administration of radioiodine $\left({ }^{131} \mathrm{I}\right)$. One consideration in this therapy is the radiation exposure risks, which have led the Sri Lankan Regulatory Authority to lay down criteria on releasing patients from hospitals when the therapy procedure involves ${ }^{131} \mathrm{I}$ activities greater than $1.85 \mathrm{GBq}(50 \mathrm{mCi})$. This study was carried out to assess the time dependent dose rate following the administration of ${ }^{131}$ I activities and estimate the radioiodine effective half-life $\left(\mathrm{T}_{\text {eff }}\right)$ inside the patient's body, which would be useful for releasing patients from hospitals and guide radiation protection recommendations as well. External whole body dose rates at $1.0 \mathrm{~m}$ from 60 patients were measured immediately after ${ }^{131} \mathrm{I}$ administration and at 24 hour intervals up to 5 days. These dose rates were used to estimate the $\mathrm{T}_{\text {eff }}$. The results demonstrated a bi-exponential radioiodine clearance pattern up to 5 days with $\mathrm{T}_{\text {eff }}$ values of 15.9 and 25.3 hours in the first and second phase, respectively. Also, majority of the patients could be released from the hospital after 72 hours post-therapy administration as they reach the permissible dose rate limit recommended by the regulatory authority of Sri Lanka by this time.
\end{abstract}

Keywords: Cancer patient release, effective half-life, radioiodine, thyroid cancer.

\section{INTRODUCTION}

Although medical procedures using radionuclides have increased worldwide, they represent an important source of radiation exposure to the population. One example of this procedure is administering radioactive iodine $\left({ }^{131} \mathrm{I}\right)$ to treat patients with thyroid disorders such as hyperthyroidism and thyroid cancer (Maxon \& Smith, 1990; Schlumberger, 1998). ${ }^{131} \mathrm{I}$ is administered to thyroid cancer patients with the aim of ablating thyroid remnant tissues after total thyroidectomy or to treat metastatic disease. The efficiency of such treatment is generally related to the radiation dose absorbed by the thyroid tissue and tumors (Hanscheid et al., 2006). After therapeutic administration, ${ }^{131} \mathrm{I}$ activities enter the blood circulation, being partially retained by the patient's body and is excreted mainly by the kidneys.

The therapeutic ${ }^{131} \mathrm{I}$ activities applied to treat thyroid cancer commonly range from 3.7 to $7.4 \mathrm{GBq}$, with the larger activities employed in metastatic disease. Because of the relatively high ionizing radiation field that exists near a patient's body after therapy administration, regulations are required that such patients remain hospitalized until the radiation protective measures are satisfied. Atomic Energy Authority (AEA), the regulatory body in Sri Lanka, states that radioactive patients may be released from hospitals provided that the potential of effective dose to others is not likely to exceed $5 \mathrm{mSv}$ (Atomic Energy Authority, 1999). However, the suitability of dose based, rather than activity based release criteria for radionuclide therapy patients remain controversial (Grigsby et al., 2000; Venencia et al., 2002; ICRP, 2004).

The current regulations in Sri Lanka state the need for interning patients when the administered ${ }^{131}$ I activity is greater than $1.85 \mathrm{GBq}(50 \mathrm{mCi})$ or alternatively, when the dose rate is greater than $30 \mu \mathrm{Sv} \mathrm{h}^{-1}$ at $1.0 \mathrm{~m}$ from the patient's body. In some countries including Sri Lanka, patient's dose rate measured at a fixed distance has been used as a criterion for releasing patients from hospitals (Zanzonico et al., 2000; de Carvalho et al., 
2009). Assessing this radiation exposure or the dose rate permits estimation of radioactive iodine inside a patient's body as a function of time post-therapy administration (Thomas et al., 1980). This helps the licensee to calculate the potential of radiation dose to others by means of ${ }^{131} \mathrm{I}$ effective half-time $\left(\mathrm{T}_{\text {eff }}\right)$ inside a patient's whole body.

The objective of the present study was to assess the time dependent dose rate following ${ }^{131} \mathrm{I}$ administration in thyroid cancer treatment to estimate the $\mathrm{T}_{\text {eff }}$ and establish recommendations regarding the time necessary for the patients to be hospitalized in isolated wards at the National Cancer Institute, Maharagama (NCI).

\section{METHODS AND MATERIALS}

The study population comprised 60 patients (40 women and 20 men) who required hospitalization to treat thyroid cancer with ${ }^{131} \mathrm{I}$. All the patients had previously submitted to total or near-total thyroidectomy before receiving ${ }^{131} \mathrm{I}$ therapy to ablate residual thyroid tissues or to treat metastatic disease. The patients were without any documented renal insufficiency or other medical conditions, which could alter the iodine excretion from their bodies. Thyroid hormone replacement therapy had been discontinued for an appropriate period ( $4-6$ weeks) to assure adequate hypothyroidism state when ${ }^{131}$ I activity was administered. All the patients were furnished with a written instruction guide to follow during the inpatient therapy and advised to hydrate themselves with copious fluid intake. The fluid intake and urine output volumes were not measured as the goal of this study did not address these points.

Immediately after ${ }^{131} \mathrm{I}$ administration, dose rates from the patients were measured using a radiation detector (Mini Rad Series 1000, C0002723), which was previously calibrated in $\mu \mathrm{Sv} \mathrm{h}^{-1}$. In each measurement, the dose rates at $1.0 \mathrm{~m}$ from the neck area (anterior, posterior, left and right directions) were recorded while the patient was in a seated position. Subsequent similar sets of dose rates were recorded after 1, 24, 48, 72 and $120 \mathrm{~h}$ post-therapy administration. All the measurements were taken after emptying the bladder and background radiation was subtracted from the data. The average value for each dataset (dose rates from all directions) was used in $\mathrm{T}_{\text {eff }}$ and ${ }^{131} \mathrm{I}$ activity calculation as this methodology seems less sensitive to iodine distribution inside a patient's body. The routine procedure adopted by the hospital for these patients were strictly followed and no change was made to accommodate the present study.

\section{RESULTS}

The mean ${ }^{131} \mathrm{I}$ activity administered to the patients was 4.9 GBq. Table 1 shows the mean dose rates measured at $1.0 \mathrm{~m}$ from the patients and at different times of post- ${ }^{131} \mathrm{I}$ administration. All the patients were released from the hospital on the $5^{\text {th }}$ day. One example of the variation of the dose rate with time is given in Figure 1. This figure indicates that the dose rate decays in a bi-exponential manner where a fast clearance phase is followed by a slower one. The mean $\mathrm{T}_{\text {eff }}$ to all patients obtained by means of MATLAB software were $15.8( \pm 3.1)$ and 25.5 $( \pm 5.8)$ hours for the initial fast and the second slower clearance phase, respectively. The $\mathrm{T}_{\text {eff }}$ values calculated for each patient are given in Figure 2. It is possible to extract from this figure, that for the initial phase $58 \%$ of the patients had a $\mathrm{T}_{\text {eff }}$ value between 11 and 15 hours, and $32 \%$ between 16 and 20 hours. For the slower phase these values are $43 \%$ between 21 and 25 hours and $42 \%$ between 16 and 20 hours, respectively. A comparison between the mean $\mathrm{T}_{\text {eff }}$ for all the patients and previously reported values are given in Table 2 .

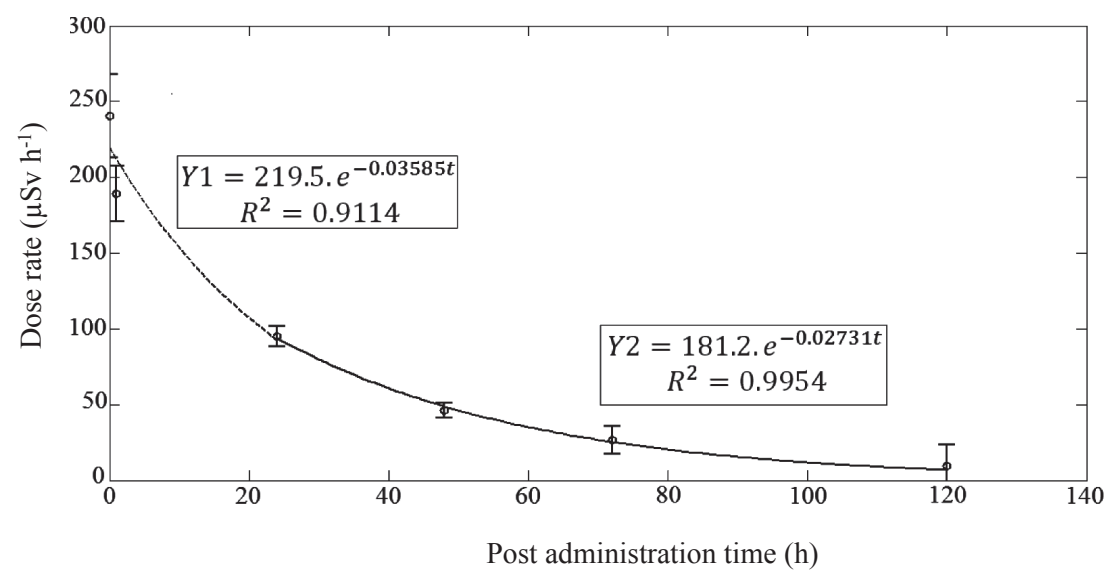

Figure 1: Pattern of clearance of body burden with administered ${ }^{131} \mathrm{I}$ 
Table 1: Dose rate $\left[\mu \mathrm{Sv} \mathrm{h}^{-1}\right]$ measured at $1.0 \mathrm{~m}$ from patients $(\mathrm{n}=60)$ as a function of time of post- ${ }^{131} \mathrm{I}$ activity administration

\begin{tabular}{lcccccc}
\hline Time & $0 \mathrm{~h}$ & $1 \mathrm{~h}$ & $24 \mathrm{~h}$ & $48 \mathrm{~h}$ & $72 \mathrm{~h}$ & $120 \mathrm{~h}$ \\
\hline Dose rate & $252 \pm 43$ & $132 \pm 25$ & $65 \pm 15$ & $38 \pm 14$ & $22 \pm 10$ & $5 \pm 6$ \\
Range & $174-349$ & $99-213$ & $42-106$ & $21-92$ & $10-51$ & $1-30$ \\
\hline
\end{tabular}

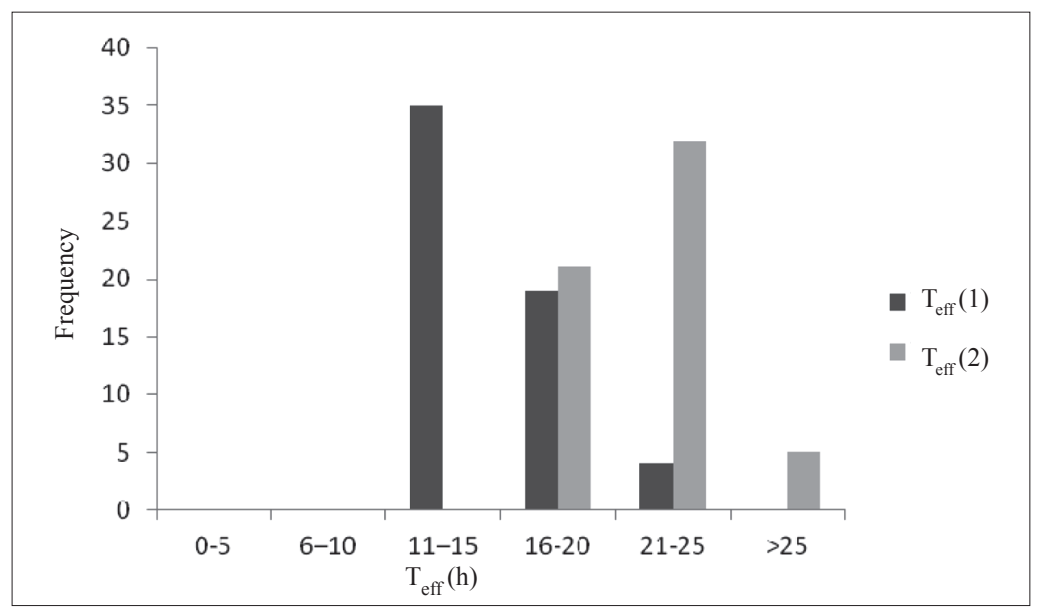

Figure 2: Distribution of effective half-time $\left(\mathrm{T}_{\text {eff }}\right)$ for the two phases

Table 2: Comparison of $\mathrm{T}_{\text {eff }}$ from this study and from current literature

\begin{tabular}{lcc}
\hline Study & $\begin{array}{c}\text { First phase } \\
\mathrm{T}_{\text {eff }}(\mathrm{h})\end{array}$ & $\begin{array}{c}\text { Second phase } \\
\mathrm{T}_{\text {eff }}(\mathrm{h})\end{array}$ \\
\hline Present study $(\mathrm{n}=60)$ & 15.9 & 25.3 \\
Ravichandran et al. $(\mathrm{n}=69)$ & 14.4 & 22 \\
Barrington et al. $(\mathrm{n}=86)$ & 12.0 & 101.7 \\
Tabei et al. $(\mathrm{n}=562)$ & 11.76 & 38.64 \\
\hline
\end{tabular}

$\mathrm{n}=$ number of subjects studied

\section{DISCUSSION AND CONCLUSION}

Surgical resection of the thyroid gland followed by ${ }^{131}$ I therapy has long been the standard treatment for differentiated thyroid cancer. The ${ }^{131} \mathrm{I} \mathrm{T}_{\text {eff }}$ in total body of the patients with intact thyroid gland is generally estimated as $5.5 \mathrm{~d}(132 \mathrm{~h})$, but in thyroidectomized patients this value is much shorter (Ravichandran et al., 2010).

The method used in this study to estimate the $T_{\text {eff }}$ was based on dose rate measurements performed during actual treatments of thyroid cancer patients. This method is somewhat crude compared to biokinetic studies where the metabolized and eliminated iodine is accounted.
However, the external dose rate method is operationally relevant since it is based on measurements of a quantity of interest in radiation protection. The principal source of error in the exposure rate measurement was probably the inaccuracy in the distance between the patient's body axis and the radiation detector.

In this study the mean dose rate measured at $1.0 \mathrm{~m}$ from the patients is presented with a range of values (Table 1) as a consequence of many variables involved such as the administered ${ }^{131}$ I activity, different patients' gender, age and body weight. However, these dose rates constitute an important information for radiation protection purposes because they are directly linked to the risk involved in the management of thyroid cancer patients after receiving ${ }^{131} \mathrm{I}$ therapy.

In the current study the dose rate from patients decreased in a bi-exponential pattern, where there is a fast clearance of radioiodine in the first day post${ }^{131} \mathrm{I}$ administration and a slower clearance after this time. The fast clearance could be partially explained by the biokinetic of ${ }^{131} \mathrm{I}$ inside the patient's body once the maximum dose rate is measured immediately after the ingestion of ${ }^{131} \mathrm{I}$ capsule by the patient and, after dissolved, the ${ }^{131}$ I activity is diluted throughout the body, in this way changing the geometry of the source, and being partially shielded by the patient's body. Also, 
the rapid clearance in the first phase corresponds to the urinary excretion of inorganic radioiodine, whereas the second phase corresponds to the organified ${ }^{131} \mathrm{I}$ with a slow excretion, although organification of ${ }^{131} \mathrm{I}$ is minimal in thyroidectomized patients (Shahhosseini et al., 2004). In a similar study by Barrington et al. (1996) with 86 patients, a bi-exponential pattern was found and the correspondent values for $\mathrm{T}_{\text {eff }}$ in the first and second phase were $0.50( \pm 0.09)$ and $4.28( \pm 1.55)$ days, respectively. In the study by Ravichandran et al. (2010), the reported values were 14.4 and 22.0 hours, respectively. The results from the present work, i.e. 15.9 and 25.3 hours, respectively (Table 2), are in agreement with both these studies.

Some researchers have revealed a tri-exponential clearance pattern on differentiated thyroid cancer patients (Castronovo et al., 1983; Sasikala et al., 1996), but such a difference in the clearance model may be related to the datasets used for $\mathrm{T}_{\text {eff }}$ calculation, the methodology applied for dose rate measurement, population size, patients' characteristics and other factors. Furthermore, it is possible that the $\mathrm{T}_{\text {eff }}$ value decreases in both phases according to the ${ }^{131} \mathrm{I}$ activity administered to patients as reported by Tabei et al. (2012) in a study with 562 patients and dosages of ${ }^{131} \mathrm{I}$ ranging from $3.7 \mathrm{GBq}(100 \mathrm{mCi})$ to 9.25 $\mathrm{GBq}(250 \mathrm{mCi})$. It was not possible to show this difference in our study due to the small sample size.

According to Pacilio et al. (2005), about $80 \%$ of the administered ${ }^{131} \mathrm{I}$ activity is eliminated from a patient's body within 48 hours, while Thompson (2001) reported that between $35 \%$ and $75 \%$ is eliminated within the first 24 hours after administration in a majority of patients.

At the National Cancer Institute (NCI) of Sri Lanka, all the patients are discharged from the hospital only when the dose rate measured at $1.0 \mathrm{~m}$ from their bodies is less than $30 \mu \mathrm{Sv} \mathrm{h}^{-1}$. Our experiment has demonstrated that the isolation time depends on the $\mathrm{T}_{\text {eff }}$ value instead of the administered ${ }^{131} \mathrm{I}$ activity. The results of this study have indicated that in 48 hours post- ${ }^{131}$ I therapy the remaining radioiodine activity in a patient's body is almost always less than $1.85 \mathrm{GBq}(50 \mathrm{mCi})$; only four patients presented a dose rate greater than $30 \mu \mathrm{Sv} \mathrm{h} \mathrm{h}^{-1}$ at this time. This suggests that a majority of the patients could be discharged from the hospital on the third day of the post-therapy administration, without a significant radiation risk to the public or family members. If the logistic of interning patients is optimized, several advantages may appear such as reducing therapy costs and increasing psychological benefits for the patients and their families. The current practice at the NCI is to discharge all patients after the fifth day post-therapy, but releasing the patients based on dose rate measurement would help to optimize this procedure while complying with the AEA regulations.

\section{REFERENCES}

1. Atomic Energy Authority of Sri Lanka (1999). Atomic Energy Safety Regulations No.1 of 1999, Regulations on Ionizing Radiation Protection, pp. 61 - 68. Atomic Energy Authority of Sri Lanka, Orugodawatta, Wellampitiya.

2. Barrington S.F., Kettle A.G., O’Doherty M.J., Wells C.P., Somer E.J. \& Coakley A.J. (1996). Radiation dose rates from patients receiving iodine-131 therapy for carcinoma of the thyroid. European Journal of Nuclear Medicine 23: $123-130$

DOI: http://dx.doi.org/10.1007/BF01731834

3. Castronovo F.P. Jr, Beh R.A. \& Veilleux N.M. (1983). Dosimetric considerations while attending hospitalized I-131 therapy patients. Journal of Nuclear Medicine Technology 10: $157-160$.

4. de Carvalho J.W., Sapienza M., Ono C., Watanabe T., Guimaraes M.I., Gutterres R., Marechal M.H. \& Buchpiguel C. (2009). Could the treatment of differentiated thyroid carcinoma with 3.7 and $5.55 \mathrm{GBq}$ of $\left({ }^{131} \mathrm{I}\right) \mathrm{NaI}$, on an outpatient basis be safe? Nuclear Medicine Community 30: $533-541$.

5. Grigsby P.W., Siegel B.A., Baker S. \& Eichling J.O. (2000). Radiation exposure from outpatient radioactive iodine $\left({ }^{131} \mathrm{I}\right)$ therapy from thyroid carcinoma. Journal of the American Medical Association 283: 2272 - 2274.

DOI: http://dx.doi.org/10.1001/jama.283.17.2272

6. Hanscheid H., Lassmann M., Luster M., Thomas S.R., Pacini F., Ceccarelli C., Ladenson P.W. \& Wahl R.L. (2006). Iodine biokinetics and dosimetry in radioiodine therapy of thyroid cancer: procedures and results of a prospective international controlled study of ablation after rhTSH or hormone withdrawal. Journal of Nuclear Medicine 47: $648-654$.

7. International Commission on Radiological Protection. (ICRP) (2004). Release of patients after therapy with unsealed radionucides. Annals of ICRP 34 (v-vi): 1 - 79.

8. Maxon H.R. \& Smith H.S. (1990). Radioiodine-131 in the diagnosis and treatment of metastatic well differentiated thyroid cancer. Endocrinology Metabolism Clinics of North America 19: 685 - 719.

9. Pacilio M., Bianciardi L., Panichelli V., Argiro G. \& Cipriani C. (2005). Management of ${ }^{131}$ I therapy for thyroid cancer, cumulative dose from in-patients, discharge planning and personnel requirements. Nuclear Medicine Community 26: $623-631$.

10. Ravichandran R., Binukumar J. \& Saadi A.A. (2010). Estimation of effective half life of clearance of radioactive Iodine $\left({ }^{131} \mathrm{I}\right)$ in patients treated for hyperthyroidism and carcinoma thyroid. Indian Journal of Nuclear Medicine 25: $49-52$.

DOI: http://dx.doi.org/10.4103/0972-3919.72686

11. Sasikala A.C., Radhakrishnan E.R., Rao P.N., Devaru S., Jayasree U., Supe S.S. \& Ravichandran R. (1996). 
Assessment of patient radioactive body burden of I -131 in the management of thyroid cancer. Indian Journal of Nuclear Medicine 11: 151 - 156.

12. Schlumberger M.J. (1998). Papillary and follicular thyroid carcinoma. The New England Journal of Medicine 338: $297-306$.

DOI: http://dx.doi.org/10.1056/NEJM199801293380506

13. Shahhosseini S., Beiki D., Dadashzadeh S., Eftekhari M., Tayebi H. \& Moosazadeh Rashti G. (2004). Radiation dose rate and urinary activity in patients with differentiated thyroid carcinoma treated with radioiodine-131: a survey in Iranian population. Hellenic Journal of Nuclear Medicine 7: $192-194$.

14. Tabei F., Asli I.N., Azizmohammadi Z., Javadi H. \& Assadi M. (2012). Assessment of radiation clearance in patients with differentiated thyroid cancer. Radiation Protection Dosimetry 152(4): 323 - 327
DOI: http://dx.doi.org/10.1093/rpd/ncs063

15. Thomas S.R., Maxon H.R., Fritz K.M., Kereiakes J.G. \& Connell W.D. (1980). A comparison of methods for assessing patient body burden following I-131 therapy for thyroid cancer. Radiology 137: $839-842$.

16. Thompson M.A. (2001). Radiation safety precautions in the management of the hospitalized (131)I therapy patient. Journal of Nuclear Medicine Technology 29: 61 - 66.

17. Venencia C.D., Germanier A.G., Bustos S.R., Giovannini A.A. \& Wyse E.P. (2002). Hospital discharge of patients with thyroid carcinoma treated with ${ }^{131} \mathrm{I}$. The Journal of Nuclear Medicine 43: $61-65$

18. Zanzonico P.B., Siegal J.A. \& St Germain J. (2000). A generalized algorithm for determining the time of release and the duration of post-release radiation precautions following radionuclide therapy. Health Physics 78: 648 659 . 